IJRMMS-D-16-00510 - edited and approved by editor

\title{
The application of a Matsuoka-Nakai-Lade-Duncan failure criterion to two porous sandstones
}

\author{
Xiaodong $\mathrm{Ma}^{1} *$, John W. Rudnicki ${ }^{2}$ and Bezalel C. Haimson ${ }^{1}$ \\ 1.Geological Engineering Program and Department of Materials Science and Engineering, \\ University of Wisconsin-Madison, WI 53706, USA
}

2. Department of Civil and Environmental Engineering and Department of Mechanical Engineering, Northwestern University, Evanston, IL 60208, USA

*corresponding author:

Xiaodong Ma

Department of Geophysics

Stanford University

397 Panama Mall Room B12, Stanford, CA 94305, USA

xma32@stanford.edu

(608) 556-4958

\begin{abstract}
We summarize two suites of recent true triaxial tests in two porous sandstones, Coconino and Bentheim. One suite of tests conducted under constant $\sigma_{2}$ and $\sigma_{3}$, which revealed the effect of $\sigma_{2}$ and $\sigma_{3}$ on rock failure. The other suite of tests, performed under constant Lode angle, determined the failure dependencies on mean stress and Lode angle. Building and modifying failure descriptions by Matsuoka-Nakai (MN) and Lade-Duncan (LD), an explicit failure criterion (modified-MNLD) that generalizes a class of failure forms is used to fit the novel loading path data of both sandstones. The determined failure descriptions fit both rocks well over a wide range of failure conditions. Then, the generated failure descriptions were further used to predict failure conditions under the constant $\sigma_{2}$ and $\sigma_{3}$ loading path. The predictions by the modifiedMNLD are generally consistent with these data. The predictions also successfully replicated the variation of $\sigma_{1 \text {,peak }}$ with $\sigma_{2}$ under constant $\sigma_{3}$, suggesting the potential of the modified-MNLD to clarify the effect of $\sigma_{2}$ on rock failure.
\end{abstract}




\section{Introduction}

The field of rock mechanics is strongly concerned with the failure of rocks. A prerequisite for these analyses requires an adequate description of failure. Among others, the

41 Coulomb failure theory (including its derivative, the Mohr-Coulomb failure criterion) is the most widely used because of its simplicity. It assumes that the major principal stress $\sigma_{1}$ at failure (or $\left.\sigma_{1 \text {,peak }}\right)$ is a linear function of only $\sigma_{3}$, an assumption that is consistent with numerous conventional triaxial compression experiments $\left(\sigma_{1}>\sigma_{2}=\sigma_{3}\right)$ in different rocks.

However, the stress condition of $\sigma_{1}>\sigma_{2}=\sigma_{3}$ is not representative of the state of stress in the Earth's crust. Numerous in situ stress measurements have indicated that the crustal stress conditions are fully three-dimensional (where $\sigma_{1} \geq \sigma_{2} \geq \sigma_{3}$ ) [1-4]. Even when the crustal stress state might be approximated as $\sigma_{2} \approx \sigma_{3}$, the stress state near perturbing structures, such as boreholes, tunnels and faults, will be fully three-dimensional. True triaxial experiments replicating realistic crustal stress conditions have revealed that $\sigma_{2}$ has an indisputable effect on the stress state and nearly all aspects of failure [5-7]. For this reason, Coulomb theory and other two-dimensional failure descriptions, which neglect the effect of $\sigma_{2}$, are not suitable for describing rock failure in most situations. Adequate three-dimensional failure theories that incorporate three generally unequal principal stresses are needed to describe true triaxial failure data. Theoretical failure descriptions by Nadai, Mogi, Lade-Duncan and Matsuoka-Nakai are among the better known. These theories were found to suit different rock types and stress regimes to varying degrees. However, some of them are not suitable to model soft rocks, the failure of which evolve from shear-induced dilational failure to compactive failure mode as the mean stress increases [7-9].

In this study, we summarize recent true triaxial test results in two porous sandstones tested under a common true triaxial loading path (constant $\sigma_{2}$ and $\sigma_{3}$ ) [9] and a novel true triaxial

62 loading path (constant Lode angle and $\sigma_{3}$ ) [10]. A recent failure criterion suggested by Rudnicki 63 [11], modified from Lade-Duncan and Matsuoka-Nakai criteria, was employed to fit the novel 64 test data of the two sandstones. The generated failure descriptions were further used to predict 65 failure conditions of these rocks under true triaxial loading paths.

\section{True triaxial testing using common and novel loading paths}


Extensive suites of true triaxial experiments in two porous sandstones (Coconino, 17.5\% porosity; Bentheim, $24 \%$ porosity) were recently conducted using a common and a novel loading path $[9,10,12,13]$. The common loading path tests were carried out to determine the effect of $\sigma_{2}$ on failure stress conditions, by maintaining $\sigma_{2}$ and $\sigma_{3}$ at preset magnitudes while raising $\sigma_{1}$ monotonically until failure occurred (Fig. 1). Ma and Haimson [9] demonstrated that failure of both tested sandstones is not only a function of $\sigma_{3}$, but also of $\sigma_{2}$ (Fig. 2). For a given $\sigma_{3}, \sigma_{1}$ at failure $\left(\sigma_{1 \text {,peak }}\right)$ increases as $\sigma_{2}$ is raised above $\sigma_{3}$ between tests. The maximum stress $\sigma_{1 \text {,peak }}$ reaches a maximum when $\sigma_{2}$ is about halfway between $\sigma_{3}$ and $\sigma_{1}$, and then gradually descends such that when $\sigma_{2} \approx \sigma_{1 \text {,peak, }}$ it approaches its initial magnitude when $\sigma_{2}=\sigma_{3}$.

In the common loading path tests, the three principal stress invariants (the octahedral shear and normal stresses, $\tau_{\text {oct }}$ and $\sigma_{\text {oct }}$, and the Lode angle $\Theta$ ) constantly change during loading (where $\tau_{\mathrm{oct}}=1 / 3\left[\left(\sigma_{1}-\sigma_{2}\right)^{2}+\left(\sigma_{2}-\sigma_{3}\right)^{2}+\left(\sigma_{3}-\sigma_{1}\right)^{2}\right]^{1 / 2}$, and $\sigma_{\mathrm{oct}}=\left(\sigma_{1}+\sigma_{2}+\sigma_{3}\right) / 3$ ). Here we follow Ma et al. [10] and define the Lode angle $\Theta$ as

$$
\Theta=\tan ^{-1}\left\{\left(\sigma_{1}-2 \sigma_{2}+\sigma_{3}\right) /\left[\sqrt{ } 3 \cdot\left(\sigma_{1}-\sigma_{3}\right)\right]\right\}
$$

The stress invariants are considered to be closely associated with the constitutive behavior of rocks [7], and are more convenient than principal stresses when used in three-dimensional numerical calculations. For that reason, a novel loading path was designed, which maintains a fixed $\Theta$ during the test, by keeping the least principal stress $\left(\sigma_{3}\right)$ constant and increasing incrementally the other two principal differential stresses $\left(\Delta \sigma_{2}\left[=\sigma_{2}-\sigma_{3}\right]\right.$ and $\left.\Delta \sigma_{1}\left[=\sigma_{1}-\sigma_{3}\right]\right)$ at a fixed ratio $[9,10,14]$ (Fig. 1). By keeping $\Theta$ constant, the novel loading path allowed the separation of the effect of $\sigma_{\text {oct }}$ from that of $\Theta$ on rock failure. As shown in Fig. 3, the compressive failure (in terms of the octahedral shear stress at failure, $\tau_{\mathrm{oct}}$ ) in both Coconino and Bentheim sandstones are dependent on the mean stress at failure $\sigma_{\text {oct }}$ and the Lode angle $\Theta$. Specifically, the octahedral shear stress $\tau_{\text {oct }}$ required for failure increases with $\sigma_{\text {oct }}$ but decreases with $\Theta$ when shear failure mode dominates. This is common to both sandstones. However, the dependency of failure on $\sigma_{\text {oct }}$ and $\Theta$ is reversed when compactive failure mode occurs. Compactive failure mode was evident in Bentheim sandstone under high $\sigma_{\text {oct}}$, when compaction bands were observed. The Coconino sandstone did not enter the compactive failure regime within the range of stresses applied.

In both suites of tests, the applied constant $\sigma_{3}$ magnitudes were between 0 and $150 \mathrm{MPa}$ $(0,10,20,50,80,100,120$, and $150 \mathrm{MPa}$ for Coconino sandstone, and 0, 8, 15, 30, 60, 80, 120, 
and $150 \mathrm{MPa}$ for Bentheim sandstone. In the common loading path tests, the applied $\sigma_{2}$

100 magnitudes covered the entire range between the $\sigma_{3}$ and $\sigma_{1, \text { peak }}$ [9]. In the novel loading path tests

101 of both sandstones, the applied constant Lode angle $\Theta$ values for each constant $\sigma_{3}$ were between

$102+30^{\circ}$ and $-30^{\circ}\left(+30^{\circ},+21^{\circ},+11^{\circ}, 0^{\circ}\right.$, and $-30^{\circ}$ for Coconino sandstone, and $+30^{\circ},+21^{\circ},+11^{\circ}, 0^{\circ}$,

$103-16^{\circ}$, and $-30^{\circ}$ for Bentheim sandstone) [10].

104

105

\section{True triaxal failure data in deviatoric and meridian planes}

106

107

108

109

110

The stress conditions at failure of both sandstones can be analyzed in a coordinate system with the principal stresses as axes $\left(\sigma_{1}, \sigma_{2}, \sigma_{3}\right)$. It is, however, more intuitively appealing to consider a cylindrical coordinate system with the axis of the cylinder aligned with the hydrostatic axis $\left(\sigma_{1}=\sigma_{2}=\sigma_{3}\right)$. Distance along this axis is given by $\sigma_{\text {oct. }}$ In this coordinate system, failure conditions can be expressed as

$$
F\left(\tau_{\text {oct }}, \sigma_{\text {oct }}, \Theta\right)=0
$$

The effect of $\sigma_{\text {oct }}$ on the failure of both rocks has been studied with respect to rock strength, failure plane angle, and the brittle-ductile transition [8-10].

Planes perpendicular to the hydrostatic axis are deviatoric planes. The deviatoric planes are typically used to visualize the dependency of $\tau_{\text {oct }}$ on $\Theta$ since $\sigma_{\text {oct }}$ is the same for all points in a given deviatoric plane. Radial distance in this plane is given by $\tau_{\text {oct }}$. Angular position in this plane is given by the Lode angle $\Theta$ (Eq. (1)) [7].

The Lode angle is defined here so that it is zero for deviatoric pure shear $\left(\sigma_{2}=\left(\sigma_{1}+\right.\right.$ $\left.\left.\sigma_{3}\right) / 2\right),+30^{\circ}$ for axisymmetric compression $\left(\sigma_{2}=\sigma_{3}\right)$, and $-30^{\circ}$ for axisymmetric extension $\left(\sigma_{2}=\right.$ $\left.\sigma_{1}\right)$. For an isotropic material, a $60^{\circ}$ sector defines the shape of the failure surface in the entire deviatoric plane: the remaining five sectors are given by symmetry and reflection. In this way, the experimental data of both sandstones are depicted in the deviatoric planes with closed shapes. For the Coconino sandstone (Fig. 4) the shape of the failure surfaces in the deviatoric plane gradually became more circular with increasing $\sigma_{\text {oct }}$, signifying a diminishing effect of failure on the Lode angle. For the Bentheim sandstone (Fig. 5), the shape of the failure surfaces become more circular with increasing $\sigma_{\text {oct }}$ until the compactive region is reached ( $\left.\sigma_{\text {oct }}>200 \mathrm{MPa}\right)$, then it becomes more triangular.

Figure 6 shows a typical failure surface shape of a few common failure criteria in the deviatoric plane ( $\tau_{\text {oct }}$ vs. $\Theta$, at constant $\left.\sigma_{\text {oct }}\right)$ and the meridian plane $\left(\tau_{\text {oct }}\right.$ vs. $\sigma_{\text {oct }}$, at constant $\Theta$ ) 
130 [15]. In the meridian plane, an examination of such failure surface shapes reveals the inadequacy 131 of Mohr-Coulomb criterion and Drucker-Prager criterion. The linear $\tau_{\text {oct }}$ vs. $\sigma_{\text {oct }}$ relationship of 132 these two failure descriptions is not applicable to porous rocks, which in fact show a consistently 133 declining slope with increasing $\sigma_{\text {oct }}$ for any given constant $\Theta[8,10]$. For high-porosity sandstone,

134 the variation of $\tau_{\text {oct }}$ with $\sigma_{\text {oct }}$ eventually shows a 'cap' on which $\tau_{\text {oct }}$ decreases for high $\sigma_{\text {oct }}$ [16].

135 In the deviatoric plane, the circular shape of the Drucker-Prager criterion suggests no 136 dependence of failure on Lode angle, contrary to our experimental observations [10] as well as 137 others [7]. In the deviatoric plane, the Mogi [17] failure description has unfavorable re-entrant 138 corners repeated every $2 \pi / 3$ period along the failure surface. These cause difficulty in theoretical 139 interpretation and numerical implementation. The shape of the Lade-Duncan and Matsuoka140 Nakai criteria on the deviatoric plane resembles a round-cornered triangle. The Lade-Duncan 141 criterion differs from Matsuoka-Nakai in that it predicts a higher strength at $\sigma_{2}=\sigma_{1}$, so that its 142 shape on the deviatoric plane is more rounded in general.

143 However, the experimental observations show that failure surface shape is not fixed; in 144 fact the shape evolves along successive deviatoric planes, i.e., it changes with increasing mean 145 stress (Figure 4). Such evolution was also reported [7] in a 26\% porosity Castlegate sandstone. In 146 view of this, it requires that the failure criterion should not only reflect the Lode angle 147 dependence on the deviatoric plane, but also accommodate shape change with a wide range of 148 mean stress.

3. Modified Matsuoka-Nakai-Lade-Duncan (MNLD) failure description

According to [18,19], failure criteria proposed by Matsuoka and Nakai [20] and Lade and 152 Duncan [21] can be expressed as:

$$
\text { Lade-Duncan: } \quad I_{1}^{3} / I_{3}=k_{\mathrm{LD}}
$$

155 where $k_{M N}$ and $k_{L D}(\geq 27)$ are criterion-specific material parameters. The terms $I_{1}, I_{2}, I_{3}$ are 156 principal stress invariants and they are also related to $\tau_{\text {oct }}, \sigma_{\text {oct }}$, and $\Theta$ (for details see [22, pp. 38157 41]):

$$
I_{1}=\sigma_{1}+\sigma_{2}+\sigma_{3}=3 \sigma_{\mathrm{oct}}
$$




$$
I_{2}=-\left(\sigma_{1} \sigma_{2}+\sigma_{2} \sigma_{3}+\sigma_{1} \sigma_{3}\right)=3 / 2 \tau_{\mathrm{oct}}^{2}-3 \sigma_{\mathrm{oct}}^{2}
$$

$$
I_{3}=\sigma_{1} \sigma_{2} \sigma_{3}=-\left(1 / 2^{0.5}\right) \tau_{\mathrm{oct}}^{3} \sin \Theta-(3 / 2) \sigma_{\mathrm{oct}} \tau_{\mathrm{oct}}^{2}+\sigma_{\mathrm{oct}}{ }^{3}
$$

$$
F\left({ }_{o c t}, \quad{ }_{o c t}, \quad\right)=\sqrt{\frac{4}{27}} \cdot A \cdot \sin (3) \cdot\left(\frac{o c t}{o c t, 0}\right)^{3}+\left(\frac{o c t}{o c t, 0}\right)^{2} \quad 1=0
$$

163

164

166

167

168

169

170

172

173 which was introduced in [11], and was modified from the Matsuoka and Nakai [20] and Lade and Duncan [21] criteria. Equation (5) (or 'modified-MNLD') had been previously employed as a yield function for predicting the failure-plane angle [10,23].

In Eq. (5), $A$ and $\tau_{\text {oct }, 0}$ are parameters that can depend on $\sigma_{\text {oct }}$. For deviatoric pure shear $(\Theta$ $=0$ ) the first term in Eq. (5) vanishes and Eq. (5) becomes:

$$
\tau_{\mathrm{oct}}=\tau_{\mathrm{oct}, 0}\left(\sigma_{\mathrm{oct}}\right)
$$

Thus, $\tau_{\text {oct }, 0}$ describes the mean stress dependence of $\tau_{\text {oct }}$ in deviatoric pure shear. The parameter $A$ controls the shape of the failure surface in the deviatoric plane (Fig. 7). In particular, it sets the difference in the values of $\tau_{\text {oct }}$ for axisymmetric compression and axisymmetric extension (at the same mean stress). For $A=0$, Eq. (5) reduces to Eq. (6) and the shape is simply a circle. For $A=$ 1 , the shape is triangle, as for a Rankine material for which failure occurs at a critical value of the least compressive stress $\sigma_{3}$. For $A=-1$ the shape is also a triangle but inverted from that for $A$ $=1$. For $A$ between -1 and 1 , the roots of Eq. (5) (for $\tau_{\mathrm{oct}} / \tau_{\mathrm{oct}, 0}$ ) are real and the relevant root is that closest to one. For $A$ outside this range, two of the roots are complex conjugates and the failure surface is non-convex.

For particular choices of $A$ and $\tau_{\mathrm{oct}, 0}$, Eq. (5) reduces to the forms for Matsuoka and Nakai [20] or Lade and Duncan [21] (for details see [11]). Choosing

$$
{ }_{o c t, 0}=\frac{o c t}{3} \sqrt{\frac{k_{L D} 27}{k_{L D}}}
$$

$$
A=\sqrt{\frac{k_{L D}-27}{k_{L D}}}
$$


reduces Eq. (5) to the formulation by Lade and Duncan [21] and choosing

$$
\begin{aligned}
& { }_{o c t}, 0 \\
& =\frac{o c t}{3} \sqrt{\frac{k_{M N} 9}{k_{M N} 3}} \\
& A=\sqrt{\frac{3 k_{M N}^{2}\left(k_{M N} 9\right)}{\left(k_{M N} 3\right)^{3}}}
\end{aligned}
$$

reduces Eq. (5) to the Matsuoka and Nakai [20] formulation. As shown by Eq. (7) and (8), Matsuoka and Nakai (MN) and Lade and Duncan (LD) assume constant $A$ and linear dependency of $\tau_{\mathrm{oct}, 0}$ on mean stress. Therefore, $\mathrm{MN}$ and LD dictate fixed shape on the deviatoric plane and meridian plane with no evolution with mean stress (although they could be modified to accommodate non-linear $\sigma_{\text {oct }}$-dependency $\left.[18,19]\right)$. By comparison, Eq. (5) is more flexible in that $A$ and $\tau_{\text {oct, } 0}$ can be chosen to fit experimental data. This is the procedure that we adhere to in succeeding sections.

We follow [11] in referring to Eq. (5) as a modified Matsuoka-Nakai \& Lade-Duncan (hereafter modified-MNLD) criterion. An equation of this form was used in [23] as a yield condition for predicting the failure angle in a siltstone, but here we use it as a condition for the stress state at failure.

\section{The application of modified-MNLD to Coconino and Bentheim sandstones}

The novel loading path true triaxial test data obtained by Ma et al. [10] was used to determine the expressions of $\tau_{\text {oct }, 0}$, and $A$ as functions of $\sigma_{\text {oct }}$. The specific form of $\tau_{\text {oct }, 0}=\tau_{\text {oct }, 0}$ $\left(\sigma_{\text {oct }}\right)$ was simply derived from the variation of $\tau_{\text {oct }}$ with $\sigma_{\text {oct }}$ under deviatoric pure shear $\left(\Theta=0^{\circ}\right)$. Once $\tau_{\text {oct }, 0}$ was determined $A$ was the only unknown parameter. The values of parameter $A$ corresponding to each failure datum $\left(\tau_{\text {oct }}, \sigma_{\text {oct }}\right)$ were calculated via Eq. $(5)$, except for the pure shear test series (because when $\Theta=0^{\circ}$, the first term that contains $A$ vanishes). Since $A$ is prescribed as a function of $\sigma_{\text {oct }}$, i.e., $A=A\left(\sigma_{\text {oct }}\right)$, the variation of the calculated values of $A$ with $\sigma_{\text {oct }}$ was empirically fitted to yield the specific expression $A=A\left(\sigma_{\text {oct }}\right)$. The obtained $A\left(\sigma_{\text {oct }}\right)$ and $\tau_{\text {oct }, 0}\left(\sigma_{\text {oct }}\right)$ were substituted into Eq. (5), which was then deemed complete and ready for 
application. A flow chart illustrating the failure prediction process for both common and novel loading path tests is provided in Fig. 8.

\subsubsection{Coconino sandstone}

In Coconino sandstone, the specific form of $\tau_{\text {oct }, 0}$ represents the variation of $\tau_{\text {oct }}$ with $\sigma_{\text {oct }}$ under pure shear $\left(\Theta=0^{\circ}\right)$ [10]. The trend is well fitted by a second-order polynomial equation:

$$
\tau_{\text {oct }, 0}\left(\sigma_{\text {oct }}\right)=8.377+0.697 \sigma_{\text {oct }}-0.00054 \sigma_{\text {oct }}^{2} \quad\left(R^{2} \approx 1\right)
$$

Values of $A$ were calculated by inserting the specific form of $\tau_{\text {oct, } 0}$ (Eq. (9)) into Eq. (5). Figure 9 shows the variation of calculated $A$ with $\sigma_{\text {oct }}$. Each data point corresponds to a particular stress state at failure in the novel loading path tests. $A$ steadily declines with the rise in $\sigma_{\text {oct }}$, though at low $\sigma_{\text {oct }}$ levels an initial minor increase was noticeable for $\Theta=+30^{\circ}\left(\sigma_{2}=\sigma_{3}\right)$. This overall decline of $A$ occurs regardless of the respective Lode angle $\Theta$. The extent of decrease in $A$ with $\sigma_{\text {oct }}$ appears to become more significant from $\Theta=+30^{\circ}$ to $-30^{\circ}$. For a constant $\sigma_{\text {oct }}$, $A$ slightly decreases by about 0.2 as $\Theta$ varies from $+30^{\circ}\left(\sigma_{2}=\sigma_{3}\right)$ to $-30^{\circ}\left(\sigma_{2}=\sigma_{1}\right)$, albeit with substantial dispersion. The mean value of $A$ is 0.6 . Nevertheless, a linear variation of $A$ with $\sigma_{\text {oct }}$ (Fig. 9) fits the trend of the data adequately:

$$
A\left(\sigma_{\text {oct }}\right)=1.019-0.002 \cdot \sigma_{\text {oct }} \quad\left(R^{2} \approx 0.54\right)
$$

However, extrapolation of the linear fit to low values of $\sigma_{\text {oct }}$, outside the range of the data, leads to values of $A>1$. Although this feature could be eliminated by using a cut-off or a more elaborated fitting for low values of $\sigma_{\text {oct }}$, for simplicity we use Eq. (10). This does, however, lead to some unrealistic predictions for low values of $\sigma_{\text {oct }}$.

\subsubsection{Bentheim sandstone}

For Bentheim sandstone, $\tau_{\text {oct }, 0}\left(\sigma_{\text {oct }}\right)$ was also derived from the deviatoric pure shear data series $\left(\Theta=0^{\circ}\right)$ in the novel loading path tests [10]. A second-order polynomial equation was fitted to the data set:

$$
\tau_{\text {oct }, 0}\left(\sigma_{\text {oct }}\right)=-1.445+0.833 \sigma_{\text {oct }}-0.002 \sigma_{\text {oct }}^{2} \quad\left(R^{2} \approx 0.86\right)
$$

The calculated values of $A$ as a function of $\sigma_{\text {oct }}$ for each constant $\Theta$ are shown in Fig. 9. $A$ typically declined with the rise in $\sigma_{\text {oct }}$, regardless of the specific Lode angle; between constant Lode angles, for a constant $\sigma_{\text {oct }}, A$ appears to decrease as $\Theta$ evolves from $+30^{\circ}\left(\sigma_{2}=\sigma_{3}\right)$ to $\Theta=$ - 
$30^{\circ}\left(\sigma_{2}=\sigma_{1}\right)$. This trend is similar to that found in Coconino sandstone. The mean value of $A$ is

2380.33 , and a linear equation can be fit coarsely to $A\left(\sigma_{\text {oct }}\right)$ :

$$
A\left(\sigma_{\text {oct }}\right)=1.245-0.006 \sigma_{\text {oct }}
$$

$$
\left(R^{2} \approx 0.41\right)
$$

Again, extrapolation to low values of $\sigma_{\mathrm{oct}}$ leads to $A>1$ and some unrealistic predictions, but as this lies outside the range of the data, we simply use the linear form.

\subsection{Application to the novel loading path data}

\subsubsection{Coconino sandstone}

Given the input values of $\Theta$ and $\sigma_{3}$, the prediction of $\sigma_{1 \text {,peak }}$ returns the theoretical values

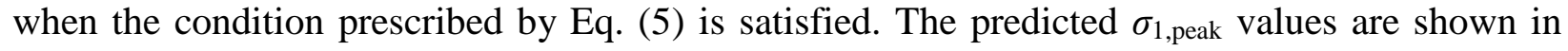
Fig. 10 for each constant Lode angle. Predicted $\sigma_{1 \text {,peak }}$ underestimates slightly the experimental magnitudes at $\sigma_{2}=\sigma_{3}\left(\Theta=+30^{\circ}\right)$ and $\sigma_{2}=\sigma_{1}\left(\Theta=-30^{\circ}\right)$. For $\sigma_{2}=\sigma_{3}$, the prediction consistently generates lower $\sigma_{1 \text {,peak }}$ than the experimental value by about $50 \mathrm{MPa}$, except for $\sigma_{3}=0$

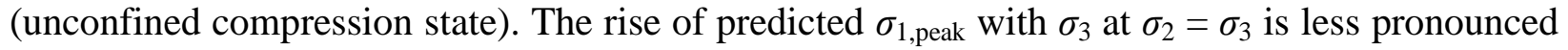
for $\sigma_{3} \leq 50 \mathrm{MPa}$ as compared to the experimental data. At $\sigma_{2}=\sigma_{1}$, the predicted $\sigma_{1 \text {,peak }}$ is only slightly less than the experimental value, by no more than $20 \mathrm{MPa}$ (Fig. 10). Again, the only exception is at $\sigma_{3}=0$ (biaxial compression state), where the experimental $\sigma_{1 \text {,peak }}$ exceeds the predicted value by $20 \mathrm{MPa}$.

At intermediate Lode angles $\left(\Theta=+21^{\circ},+11^{\circ}\right.$, and $\left.0^{\circ}\right)$, the predictions of $\sigma_{1 \text {,peak }}$ agree well with experiments (Fig. 10). The best match is found at deviatoric pure shear $\left(\Theta=0^{\circ}\right)$. This is obvious since pure shear test data were used to derive the relationship $\tau_{\text {oct }, 0}=\tau_{\text {oct }, 0}\left(\sigma_{\text {oct }}\right)$.

The deviation of the predicted $\sigma_{1 \text {,peak }}$ from the experimental data given the same $\left(\Theta, \sigma_{3}\right)$ induces changes in both $\tau_{\text {oct }}$ and $\sigma_{\text {oct }}$, which are not maintained constant under the novel loading path. As a result, a point-to-point comparison in the $\tau_{\text {oct }}$ vs. $\sigma_{\text {oct }}$ domain is obscure and therefore not pursued. Instead, a continuous variation of $\tau_{\text {oct }}$ with $\sigma_{\text {oct }}$ is predicted and compared against the experimental data (Fig. 3). The predicted $\tau_{\text {oct }}$ increases monotonically with the rise in $\sigma_{\text {oct, f, in }}$ agreement with the experimental results. Similar to the comparison in the $\sigma_{1, \text { peak }}-\sigma_{3}$ domain (Fig. $10)$, the best correlation is obtained under pure shear $\left(\Theta=0^{\circ}\right)$, which is naturally the case since the prediction are based on $\Theta=0^{\circ}$ data series. The difference between the experimental results and the theoretical prediction at other Lode angles increased as the deviatoric stress state approached the axisymmetric compression $\left(\Theta=+30^{\circ}\right.$, i.e., $\left.\sigma_{2}=\sigma_{3}\right)$. 
The effect of Lode angle on failure is also illustrated in the deviatoric plane $\left(\tau_{\text {oct }}-\Theta\right.$ domain with constant $\left.\sigma_{\text {oct }}\right)$. Deviatoric planes of various constant $\sigma_{\text {oct }}(=50,150,250,350,450$ $\mathrm{MPa}$ ) were selected, as was shown in the novel test analysis. In each deviatoric plane, the predicted $\tau_{\text {oct }}$ covers the deviatoric stress states from $\sigma_{2}=\sigma_{3}$ to $\sigma_{2}=\sigma_{1}$ (corresponding to Lode angle in the range $-30^{\circ} \leq \Theta \leq+30^{\circ}$ ), and was further extended to cover $-180^{\circ} \leq \Theta \leq+180^{\circ}$ via symmetry. This results in a continuous, closed failure envelope in the deviatoric plane (Fig. 4). Because the novel loading path did not maintain a constant $\sigma_{\text {oct }}$ throughout the test, the experimental data could not be directly compared with the theoretical predictions for the same $\sigma_{\text {oct }}$ (i.e., on the same deviatoric plane). To address this, based on the $\tau_{\text {oct }}$ vs. $\sigma_{\text {oct }}$ fitting curves to the novel loading path test results [10], the values of $\tau_{\text {oct }}$ were extrapolated at $\sigma_{\text {oct }}=50,150,250$, 350, $450 \mathrm{MPa}$. The extrapolated $\tau_{\text {oct }}$ are compared with the predicted failure envelope on those deviatoric planes. The predicted failure envelopes agree well with the extrapolated results. However, a noticeable discrepancy at $\sigma_{2}=\sigma_{3}$ was found in the deviatoric plane, in that $\tau_{\text {oct }}$ was overestimated at $\sigma_{\mathrm{oct}, \mathrm{f}}=150$ and $250 \mathrm{MPa}$, and underestimated at $\sigma_{\mathrm{oct}}=450 \mathrm{MPa}$.

The predictions complement the experiments by demonstrating an unambiguous effect of $\sigma_{\text {oct }}$ on the variations of $\tau_{\text {oct }}$ with $\Theta$. This effect is best illustrated by projecting these predicted failure envelopes in one single deviatoric plane. Shown in Fig. 11, the failure envelope confined area consistently grows as $\sigma_{\text {oct }}$ is raised, though at a decreasing rate. This rate change is consistent with the declining slope of the $\tau_{\text {oct }}$ vs. $\sigma_{\text {oct }}$ trend (Fig. 3). The shape of the failure envelopes becomes increasingly circular, signifying a diminishing effect of the Lode angle on $288 \tau_{\text {oct }}$ sandstone was identical to that followed in Coconino sandstone. For the test series of constant $\Theta$, $\sigma_{3}$ was varied from test to test, and the experimental $\sigma_{1 \text {,peak }}$ was compared with the theoretical 294 prediction at the same $\sigma_{3}$ level. At both axisymmetric stress conditions $\left(\Theta= \pm 30^{\circ}\right)$, the prediction yields results that closely resemble the experimental ones (Fig. 10), with the experimental $\sigma_{1 \text {,peak }}$ 296 being greater than the predicted by no more than $25 \mathrm{MPa}$ for $\sigma_{3}$ between 30 and $100 \mathrm{MPa}$. The 297 predictions at $\sigma_{3}=0 \mathrm{MPa}$ for $\sigma_{2}=\sigma_{3}$ and $\sigma_{2}=\sigma_{1}$ and, yield unrealistic solutions and are not shown. As noted earlier, this occurs because linear extrapolation of Eq. (12) causes the values of 
$A$ for $\sigma_{3}=0 \mathrm{MPa}$ to exceed +1 . Consequently, stress conditions at failure for $\sigma_{3}=0 \mathrm{MPa}$ series were not pursued in the subsequent analysis.

The predicted stress conditions at failure were further analyzed in the $\tau_{\text {oct }}$ vs. $\sigma_{\text {oct }}$ domain, for each constant Lode angle. A continuous variation of the predicted $\tau_{\text {oct }}$ with $\sigma_{\text {oct }}$ is shown in Fig. 3. Generally, the predicted $\tau_{\text {oct }}$ vs. $\sigma_{\text {oct }}$ trends follow the experimental data in that the rise in $\sigma_{\text {oct,f }}$ brings about the increase of $\tau_{\text {oct }}$ at first, reaches a peak at some level of $\sigma_{\text {oct }}$, and then declines for larger $\sigma_{\text {oct }}$. The exception is that the prediction yields abnormal results for $\sigma_{2}=\sigma_{3}$ series when $\sigma_{\text {oct }} \leq 50 \mathrm{MPa}$ (the unusual whip shown in Fig. 3). Again, this occurs because extrapolation of parameter $A$ using Eq. (12) for low $\sigma_{\text {oct }}$ values exceeds the limit of validity of parameter $A$. This unrealistic prediction could be improved given a better-constrained dependency on $\sigma_{\text {oct }}$.

In contrast to the results for the Coconino sandstone, for which $\tau_{\text {oct }}$ rises continuously with $\sigma_{\mathrm{oct}}$, the results for the Bentheim sandstone shown in Fig. 3 indicate a region of decreasing $\tau_{\text {oct }}$ with $\sigma_{\text {oct. }}$ Although based on relatively few data points, this suggests the emergence of a 'cap' that would be more prominent with larger values of $\sigma_{\text {oct }}$. The 'cap' regime suggests the failure mode is primarily by compaction, in which the high confinement induces high stress concentration to break the sandstone grains and high shear stress is no longer critical. As it implies, a limiting case is that sufficiently high confinement may cause failure in a porous sandstone without any applied shear stress, i.e., hydrostatic stress condition. A complete 'cap' under conventional triaxial condition has been mapped in several porous sandstones with porosities comparable to that of Bentheim sandstone [8], and the emergence of 'cap' in the Bentheim sandstone is expected at the applied stress level.

A clear variation of the predicted $\tau_{\text {oct }}$ vs. $\sigma_{\text {oct }}$ trend with Lode angle $\Theta$ is observed (Fig. 3). For a constant $\tau_{\text {oct }}$, the $\sigma_{\text {oct }}$ required for failure unequivocally increases when $\Theta$ varies from $+30^{\circ}$ to $-30^{\circ}$. This trend is in qualitative agreement with the experimental results [10], though the experimental trend is obscured by significant dispersion. In Bentheim sandstone, the critical $\sigma_{\text {oct }}$ level where $\tau_{\text {oct }}$ reaches its maximum, rises consistently as the corresponding constant $\Theta$ approaches $-30^{\circ}\left(\sigma_{2}=\sigma_{1}\right)$, suggesting an increased $\sigma_{\text {oct }}$ magnitude at which the cap was developed.

It is interesting to note that in Fig. 3 , when $\sigma_{\text {oct }} \approx 200 \mathrm{MPa}$, all predicted curves converge to $\tau_{\text {oct }} \approx 90 \mathrm{MPa}$, regardless of the specific Lode angle. The convergence indicates that the Lode 
angle has no influence on failure (in terms of $\tau_{\text {oct }}$ ) at $\sigma_{\text {oct }} \approx 200 \mathrm{MPa}$. This phenomenon is also illustrated in the deviatoric plane $\left(\tau_{\text {oct }}-\Theta\right)$. As shown in Fig. 5, the failure surface at $\sigma_{\text {oct }}=200$ MPa takes a circular shape, indicating no variation $\tau_{\text {oct }}$ on $\Theta$; this trend could be best described by the Drucker-Prager failure criterion [24]. For constant $\sigma_{\text {oct }}<200 \mathrm{MPa}, \tau_{\text {oct }}$ at failure when $\sigma_{2}=$ $\sigma_{3}$ is greater than that at $\sigma_{2}=\sigma_{1}$, so that the failure surface shape protrudes at $\Theta=+30^{\circ},+150^{\circ}$, and $-90^{\circ}$, resembling a round-cornered triangle. The triangular shape could be adequately described by the Matsuoka and Nakai [20] or Lade and Duncan [21] criterion. As $\sigma_{\text {oct }}$ approaches $200 \mathrm{MPa}$, the dependence of $\tau_{\text {oct }}$ on $\Theta$ diminishes; thus the failure surface shape gradually becomes equi-dimensional. For $\sigma_{\text {oct }}>200 \mathrm{MPa}$, the $\tau_{\text {oct }}$ vs. $\sigma_{\text {oct }}$ curves diverge again but take a different trend as compared to that at $\sigma_{\text {oct }}<200 \mathrm{MPa}$ : the shape of the failure surface in the deviatoric plane elongates at $\Theta=-150^{\circ},-30^{\circ}\left(\sigma_{2}=\sigma_{1}\right)$ and $+90^{\circ}$. Such variation of the failure surface shape in the deviatoric plane with increasing $\sigma_{\text {oct }}$ is recaptured in Fig. 11, showing the predicted $\tau_{\text {oct }}$ only. The variation of the failure surface shape with $\sigma_{\text {oct }}$ generally agrees with the novel loading path experimental results. An apparent discrepancy is found at $\sigma_{\mathrm{oct}}=300 \mathrm{MPa}$ and $\Theta$ between pure shear and axisymmetric compression. Because the applied $\sigma_{\text {oct }}$ in the experiments at these Lode angles only reaches a maximum of $250 \mathrm{MPa}$, the extrapolated $\tau_{\text {oct }}$ at $\sigma_{\text {oct }}=300 \mathrm{MPa}$ requires verification with additional experimental data.

\subsection{Application to the common loading path data}

The application of the modified-MNLD failure description to the novel loading path test data is essentially data fitting rather than prediction. Because the modified-MNLD fits Coconino and Bentheim sandstones data under the novel loading path, we test its applicability in both sandstones to results under the common loading path.

\subsubsection{Coconino sandstone}

Under the common loading path, $\sigma_{1 \text {,peak }}$ was calculated using Eq. (5) applied to constant $\sigma_{2}$ and $\sigma_{3}$ conditions [9]. For each constant $\sigma_{3}$ series, $\sigma_{1 \text {,peak }}$ was calculated by increasing the variable $\sigma_{2}$ in small increments from its lower limit $\left(=\sigma_{3}\right)$ to the upper end $\left(=\sigma_{1}\right)$. The predicted continuous $\sigma_{1 \text {,peak }}$, and the experimental data points were then compared (Fig. 2). The failure prediction in Coconino sandstone generally replicates the variation of $\sigma_{1 \text {,peak }}$ with $\sigma_{2}$ observed experimentally. For constant $\sigma_{3}$, the increase of $\sigma_{2}$ first brings about the rise in $\sigma_{1 \text {,peak, which }}$ 
reaches its maximum at an intermediate level of $\sigma_{2}$, then consistently declines for larger $\sigma_{2} . \sigma_{1 \text {,peak }}$ for a constant $\sigma_{3}$ level (i.e., $\sigma_{1 \text {,peak }}^{M A X}$ ) is compared with its base value at $\sigma_{2}=\sigma_{3}$.

\subsubsection{Bentheim sandstone}

The prediction in Bentheim sandstone for given constant $\sigma_{2}$ and $\sigma_{3}$ conditions simulates its common loading path tests [9]. The results are shown in the $\sigma_{1 \text {,peak }}-\sigma_{2}$ domain, and compared with the experimental data for each constant $\sigma_{3}$ (Fig. 2). The failure predictions in Bentheim sandstone generally agree with the experimental observation, in which $\sigma_{1 \text {,peak }}$ is clearly a function

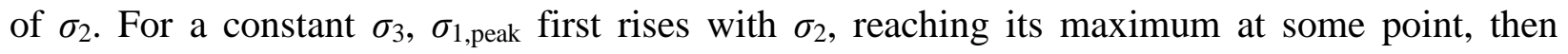
declines for larger $\sigma_{2}$ until $\sigma_{2}=\sigma_{1 \text {,peak }}$. The correlation between the experimental results and the predictions is moderate-to-strong overall although the predictions at low $\sigma_{3}$ level (corresponding to $\sigma_{\mathrm{oct}} \leq 50 \mathrm{MPa}$ ) are poor. In particular, the prediction overestimates $\sigma_{1 \text {,peak }}$ at $\sigma_{3}=\sigma_{2}=8 \mathrm{MPa}$ by

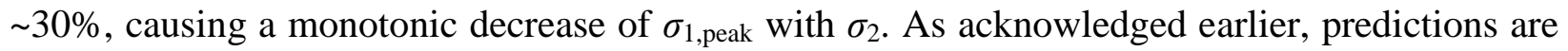
poor for the $\sigma_{3}=0$ series because of the oversimplified fitting of $A$ at low values of $\sigma_{\text {oct }}$ and this also affects other predictions for low $\sigma_{3}$.

\section{Discussion}

The good agreement between the theoretical description and the experimental results in both sandstones subjected to both loading paths demonstrated the applicability of the modifiedMNLD [11] to model failure through the range of compressive stress magnitudes applied $\left(\sigma_{3}\right.$ between 0 and $150 \mathrm{MPa}$ ). Its superior performance over common three-dimensional failure descriptions such as Nadai and Mogi descriptions is due to the flexibility of the Eq. (5) in describing failure in terms of the variation of $\tau_{\text {oct }}$ with $\Theta$ for constant $\sigma_{\text {oct }}$, and the variation of $\tau_{\text {oct }}$ with $\sigma_{\text {oct }}$ for constant $\Theta$. Through the explicit use of parameter $A$ as a function of $\sigma_{\text {oct }}$, the evolution of failure surface shape in the deviatoric plane ( $\tau_{\text {oct }}-\Theta$ domain) with $\sigma_{\text {oct }}$ is included. This is particularly advantageous in modeling those rocks in which failure is highly sensitive to the compressive stress magnitudes. In contrast, many other failure expressions have a rigid mathematical form, and therefore yield a failure surface with little or no variation in shape. In this sense, the modified-MNLD failure theory represents a class of failure descriptions. There are other failure descriptions with similar flexibility such as Willam and Warnke criterion [25]. For example, Descamps et al. [26] used the Willam and Warnke criterion [25] to model the failure 
surface for a highly porous Sorcy limestone (porosity $\approx 27.5 \%$ ) and was in good agreement of their true triaxial test data.

Advanced failure descriptions such as those by Rudnicki [11] and Willam and Warnke [25] are straightforward to use in a general three-dimensional framework [18,19,27]. These descriptions share certain common features. First is to allow failure $\left(\tau_{\text {oct }}\right)$ variation between axisymmetric compression and extension states $\left(\sigma_{2}=\sigma_{3}\right.$ and $\left.\sigma_{2}=\sigma_{1}\right)$ for constant $\sigma_{\text {oct. }}$ The description by Nadai [28] offers no such variation. Second is differentiability to ensure the theoretical function $F\left(\tau_{\text {oct }}, \sigma_{\text {oct }}, \Theta\right)=0$ varies smoothly and continuously across any Lode angle. The final feature is that the failure surface in deviatoric planes should be convex [29]. The description by Mogi [17] has poblems of both differentiability and non-convexity at those cusps.

Rudnicki's modified-MNLD failure description [11] also qualitatively replicates the variation of $\sigma_{1 \text {,peak }}$ with $\sigma_{2}$ for constant $\sigma_{3}$ as observed in common loading path tests in Coconino and Bentheim sandstones [9]. This is a significant extension of the applicability of Eq. (5) since the failure description is independently constrained by the novel loading path test data [10]. It shows that the failure (in terms of $\tau_{\text {oct }}$ ) dependence on $\Theta$ and $\sigma_{\text {oct }}$ is interconnected with the dependence of failure (in terms of $\sigma_{1, \text { peak }}$ ) on $\sigma_{2}$. Furthermore, it implies that the evolving $\sigma_{2}$ effect with increasing $\sigma_{3}$ is a result of the characteristic dependencies of $\tau_{\text {oct }}$ on $\Theta$ and $\sigma_{\text {oct }}$.

In some failure theories, the $\sigma_{2}$ - dependency of $\sigma_{1 \text {,peak }}$ evolves negligibly with $\sigma_{3}$. This could be attributed to the absence of curvature change in $\tau_{\text {oct }}$ vs. $\sigma_{\text {oct }}$ curve. For example, the failure expression [24] $\tau_{\text {oct }}=A+B \sigma_{\text {oct }}$ yields no apparent change in the $\sigma_{1 \text {,peak }}$ vs. $\sigma_{2}$ trend with $\sigma_{3}$ level because the three-dimensional friction coefficient $B$ is assumed constant. Nor does the true triaxial failure criterion of Wiebols and Cook [30] impose any apparent variation of $\sigma_{1 \text {,peak }}$ vs. $\sigma_{2}$ trend with $\sigma_{3}$. This is considered to be a direct result of their basic assumption of a constant effective friction coefficient (associated with but not equal to the friction coefficient $B$ [= $\left.\left.d \tau_{\text {oct }} / d \sigma_{\text {oct }}\right]\right)$. Therefore both failure expressions are only applicable to specific rocks within a certain stress level. In this sense, the prediction using the modified-MNLD form [11] more realistically describes the stress conditions at failure of the two porous sandstones, since both were subjected to a wide range of stresses ( $\sigma_{3}$ between 0 and $150 \mathrm{MPa}$ ).

In the prediction process, we restricted the parameter $A$ to be a function of only $\sigma_{\text {oct }}$. The trend that $A$ declines monotonically is generally the case revealed by experimental data. However, for a constant $\sigma_{\text {oct }}$, a slight decrease of $A$ as $\Theta$ varies from $+30^{\circ}$ to $-30^{\circ}$ is noticeable 
423 for both sandstones. The dependency of $A$ on $\Theta$ is not included for simplicity. It is unclear 424 whether the discrepancy between the experimental data and predictions is in fact due to our removal of the $\Theta$-dependency, which is to be warranted in future study. Including dependence of $A$ on $\Theta$ would change the basic shape of the surface in the deviatoric plane (Fig. 7). Any addition of this dependence would need to maintain the symmetry imposed by isotropy.

As acknowledged earlier, unsatisfactory predictions were found at high and low values of $\sigma_{\text {oct }}$ where a linear-fitted $A$ exceeds its range of validity $[-1,1]$. A more elaborated form of parameter $A$ could remedy this. For example, an ad hoc cut-off could be applied to restrict parameter $A$ between -1 and +1 . A more sophisticated representation of parameter $A$ with theoretical meaning is expected without compromising the simplicity of Eq. (5).

\section{Concluding Remarks}

In this study, we reviewed true triaxial failure results in two porous sandstones using a common loading path [9] and a novel loading path [10]. An explicit failure description [11] that generalizes a class of failure forms, including Matsuoka-Nakai and Lade-Duncan, was employed to fit the novel loading path (constant Lode angle) data of two sandstones. This modified-MNLD criterion generated failure descriptions for both sandstones and proved adequate for them over the wide range of applied stress conditions. The generated failure descriptions were further used to predict failure conditions of both rocks under the common loading path (constant $\sigma_{2}$ on $\sigma_{3}$ ). The prediction was satisfactorily applied to the common test data [9] and successfully replicated the effect of $\sigma_{2}$ on $\sigma_{1 \text {,peak }}$, including the typical ascending-then-descending $\sigma_{1 \text {,peak }}$ under constant $\sigma_{3}$, and an evolving $\sigma_{2}$ effect with the magnitude of $\sigma_{3}$. Therefore, we recommend the application of the modified-MNLD failure description to porous sandstones over a wide range of stress magnitudes.

\section{Acknowledgement}

This research was supported by the National Science Foundation Grant EAR-0940323 (for BCH 


\section{References}

454 [1] Haimson BC. The hydrofracturing stress measuring method and recent field results. Int. J. 455 Rock Mech. Min. Sci. Geomech. Abstr. 1978;15: 167-178.

456 [2] McGarr A, Gay NC. State of stress in the Earth's crust. Ann. Rev. Earth Planet. Sci. 457 1978;6: 405-436.

458 [3] Brace WF, Kohlstedt DL. Limits on lithospheric stress imposed by laboratory 459 experiments. J. Geophys. Res. 1980;85(B11): 6248-6252.

460 [4] Vernik L. Zoback M. Estimation of maximum horizontal principal stress magnitude from 461 stress-induced well bore breakouts in the Cajon Pass Scientific Research Borehole. J. Geophys. 462 Res. 1992;97(B4): 5109-5119.

463 [5] Haimson B. True triaxial stresses and the brittle fracture of rock. Pure Appl. Geophys. 464 2006;163: 1101-1130.

465 [6] Mogi K. Experimental rock mechanics. London: Balkema; 2007.

466 [7] Ingraham MD, Issen KA, Holcomb DJ. Response of Castlegate sandstone to true triaxial 467 states of stress. J. Geophys. Res. 2013;118(B9): 1-17.

468 [8] Wong T, Baud P. The brittle-ductile transition in porous rock: A review. J. Struct. Geol. $469 \quad 2012 ; 44: 25-53$.

470 [9] Ma X, Haimson BC. Failure characteristics of two porous sandstones subjected to true $471 \quad$ triaxial stresses. J. Geophys. Res. Solid Earth 2016;121: 6477-6498.

472 [10] Ma X, Rudnicki JW, Haimson BC. True triaxial tests in two porous sandstones: 473 experimental failure characteristics and theoretical prediction. In: Proceedings of the 48th U.S. 474 Rock Mechanics Geomechanics Symposium. Minneapolis; 1-4 June 2014.

475 [11] Rudnicki JW. Failure of Rocks in the Laboratory and in the Earth. In: Proceedings of $47622^{\text {nd }}$ International Congress on Theoretical and Applied Mechanics. Adelaide; 24-29 August 477 2008. pp. 199-215.

478 [12] Ma X. Failure characteristics of compactive, porous sandstones subjected to true triaxial 479 stresses. Ph.D thesis. University of Wisconsin-Madison, Madison, Wisconsin; 2014. 
480 [13] Duan K, Kwok F, Ma X. DEM simulations of sandstone under true triaxial compressive 481 tests. Acta Geotechnica 2016; doi: 10.1007/s11440-016-0480-6.

482 [14] Jimenez R, Ma X. A note on the strength symmetry imposed by Mogi's true-triaxial 483 criterion. Int. J. Rock Mech. Min. Sci. 2013;64: 17-21.

484 [15] Benz T, Schwab R. A quantitative comparison of six rock failure criteria. Int. J. Rock 485 Mech. \& Min. Sci. 2008;45: 1176-1186.

486 [16] Olsson WA, Holcomb DJ. Compaction localization in porous rock. Geophys. Res. 487 Lett. 2000; 27(21): 3537-3540.

488 [17] Mogi K. Fracture and flow of rocks under high triaxial compression. J. Geophys. Res. 489 1971;76(5): 1255-1269.

490 [18] Borja RI. Plasticity Modeling \& Computation. Berlin: Springer-Verlag; 2013.

491 [19] Borja RI, Sama KM, Sanz PF. On the numerical integration of three-invariant 492 elastoplastic constitutive models. Comput. Methods Appl. Mech. Engrg. 2003;192: 1227-1258.

493 [20] Matsuoka H, Nakai T. Stress-deformation and strength characteristics of soil under three 494 different principal stresses. Proc. Japan Soc. Civil Engn. 1974;232: 59-70.

495 [21] Lade PV, Duncan JM. Elastoplastic stress-strain theory for cohesionless soil. J. Geotech. 496 Eng. Div. ASCE 1975;101(GT10): 1037-1053.

497 [22] Jæger JC, Cook NGW, Zimmerman RW. Fundamentals of rock mechanics $\left(4^{\text {th }}\right.$ ed). New 498 York: Blackwell. 2007.

499 [23] Haimson B, Rudnicki JW. The effect of the intermediate principal stress on fault 500 formation and fault angle in siltstone. J. Struct. Geol. 2010;32: 1701-1711.

501 [24] Drucker DC, Prager W. Soil mechanics and plastic analysis of limit design. Q. Appl. 502 Math. 1952;10: 157-165.

503 [25] Willam KJ, Warnke EP. Constitutive model for the triaxial behavior of concrete. In: 504 Proceedings IABSE seminar on Concrete structures subjected to triaxial stresses ISMES. 505 Bergamo; 17-18 May 1974. p. 30. 
506 [26] Descamps F, Ramos da Silva M, Schroeder C, Verbrugge JC, Tshibangu JP. Limiting 507 envelopes of a dry porous limestone under true triaxial stress states. Int. J. Rock Mech. \& Min. 508 Sci. 2012;56: 88-99.

509 [27] Bardet JP. Lode dependences for isotropic pressure-sensitive elastoplastic materials. J. $510 \quad$ Appl. Mech. ASME 1990;57: 498-506.

511 [28] Nadai A. Theory of flow and fracture of solids. Vol. 1. New York: McGraw-Hill; 1950.

512 [29] Jiang J, Pietruszczak S. Convexity of yield loci for pressure sensitive materials. Comput. 513 Geotech. 1988;5: 51-63.

514 [30] Wiebols GA, Cook NGW. An energy criterion for the strength of rock in polyaxial 515 compression. Int. J. Rock Mech. \& Min. Sci. 1968;5: 529-549. 


\section{$517 \quad$ List of figures}

518 Figure 1. Two distinct loading paths of true triaxial testing: (a) common loading path ( $\sigma_{2}$ and $\sigma_{3}$ constant, $\sigma_{1}$ increasing monotonically), and (b) novel loading path ( $\sigma_{3}$ constant, $\sigma_{2}$ and $\sigma_{1}$ rising while maintaining constant stress ratio $\left.\left(\sigma_{2}-\sigma_{3}\right) /\left(\sigma_{1}-\sigma_{3}\right)\right)$.

521 Figure 2. Variations of $\sigma_{1 \text {,peak }}$ with $\sigma_{2}$ in Coconino and Bentheim sandstones tested under the common loading path for all constant $\sigma_{3}$ levels: experimental data in solid dots and predictions using the modified-MNLD failure criterion in dashed curves.

524 Figure 3. Variations of the octahedral shear stress at failure $\left(\tau_{\text {oct }}\right)$ with the octahedral normal 525 stress at failure $\left(\sigma_{\text {oct }}\right)$ in Coconino and Bentheim sandstones: experimental data in solid dots and 526 the predictions using the modified-MNLD failure criterion in solid curves for each constant Lode 527 angle.

528 Figure 4. Comparison of stress conditions at failure in the deviatoric planes ( $\tau_{\text {oct }}-\Theta$ domain) 529 between the empirically-fitted novel loading path test data (solid dots) and the predicted failure 530 surface (solid curve) in Coconino sandstone for constant $\sigma_{\text {oct }}=50,150,250,350$, and $450 \mathrm{MPa}$.

531 Figure 5. Comparison of stress conditions at failure in the deviatoric planes $\left(\tau_{\text {oct }}-\Theta\right.$ domain) 532 between the empirically-fitted novel loading path test data (solid dots) and the predicted failure 533 surface (solid curve) in Bentheim sandstone for constant $\sigma_{\text {oct }}=50,100,150,200,250$, and 300 $534 \mathrm{MPa}$.

535 Figure 6. Typical failure envelope shapes in the deviatoric plane $\left(\tau_{\text {oct }}-\Theta\right.$ domain $)$ and the 536 meridian plane ( $\tau_{\text {oct }}-\sigma_{\text {oct }}$ domain) of some common failure descriptions: (a) Mohr-Coulomb; (b) 537 Mogi; (c) Drucker-Prager; (d) Lade-Duncan; (e) Matsuoka-Nakai. The irregular hexagon failure 538 envelop of Mohr-Coulomb (in red) in the deviatoric plane was repeated (in dash) in (b) through 539 (e) for comparison.

540 Figure 7. Variation of the failure envelope shapes with parameter $A$ on the deviatoric plane. The 541 envelopes were set to converge at pure shear in order to facilitate comparison. Note as $A$ moves 542 away from 0 , the envelope becomes increasingly distorted into triangular shape.

543 Figure 8. Flowchart illustrating the procedure of failure prediction using the modified-MNLD 544 failure criterion against common and novel loading path test data. 
545 Figure 9. Variations of inferred $A$ value with the octahedral normal stress at failure $\left(\sigma_{\text {oct }}\right)$ for all 546 constant Lode angles (excluding $\Theta=0^{\circ}$ ) in Coconino and Bentheim sandstones: the dashed line 547 represents the best linear regression of all data points.

548 Figure 10. Variations of $\sigma_{1 \text {,peak }}$ with $\sigma_{3}$ for each constant Lode angle $\Theta$ under the novel loading 549 path in Coconino sandstone (left) and Bentheim sandstone (right). The predicted conditions are 550 open circles and the experimental results are solid dots.

551 Figure 11. Predicted evolution of failure surface shapes of the Coconino and Bentheim 552 sandstones on successive deviatoric planes $\left(\tau_{\text {oct }}-\Theta\right.$ domain $)$ projected on the $\pi$-plane. 

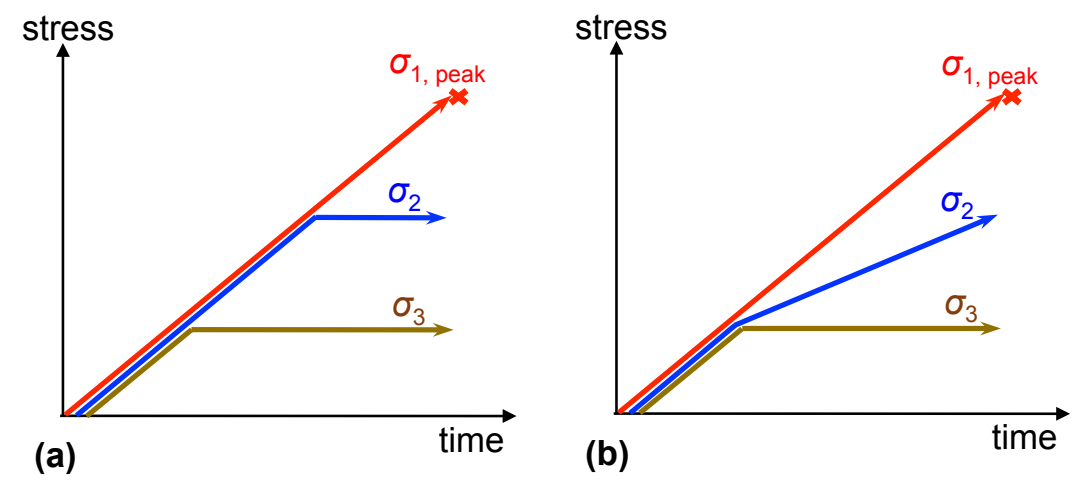

Figure 1. Two distinct loading paths of true triaxial testing: (a) common loading path ( $\sigma_{2}$ and $\sigma_{3}$ constant, $\sigma_{1}$ increasing monotonically), and (b) novel loading path $\left(\sigma_{3}\right.$ constant, $\sigma_{2}$ and $\sigma_{1}$ rising while maintaining constant stress ratio $\left(\sigma_{2}-\sigma_{3}\right) /\left(\sigma_{1}-\sigma_{3}\right)$. 

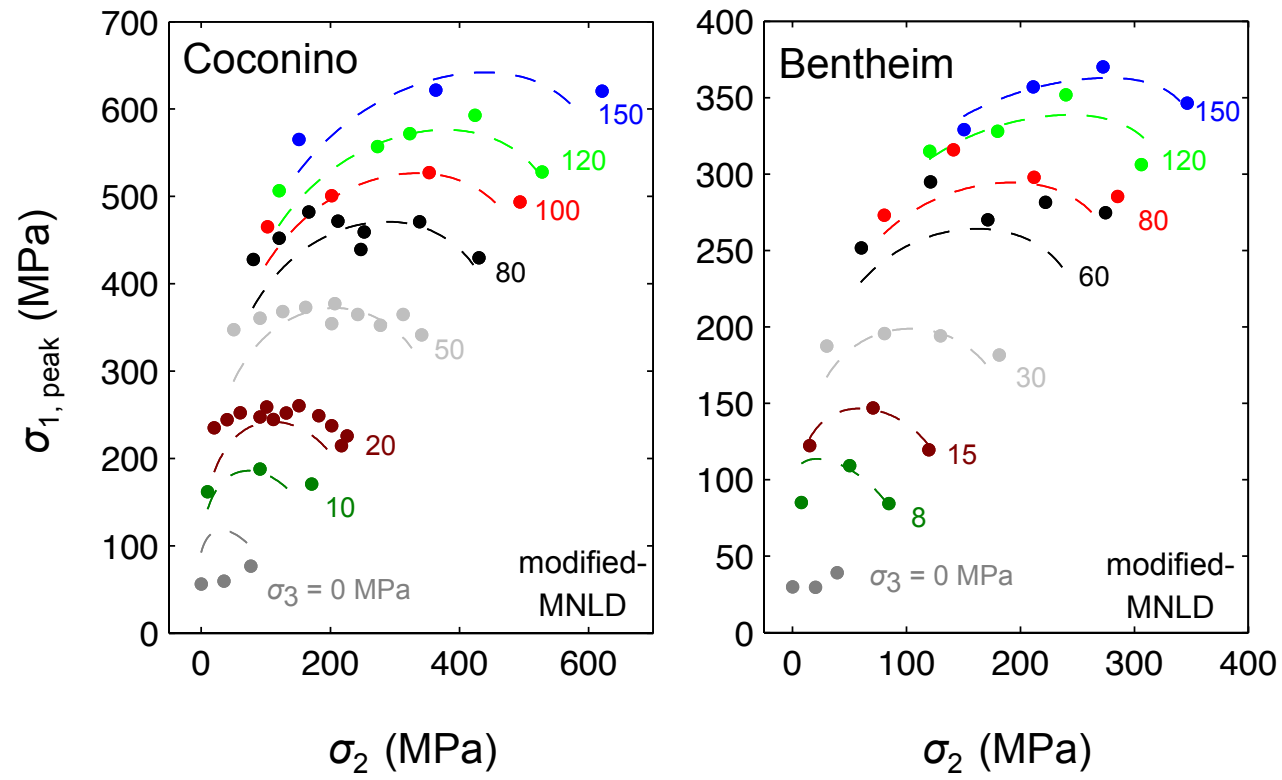

Figure 2. Variations of $\sigma_{1 \text {,peak }}$ with $\sigma_{2}$ in Coconino and Bentheim sandstones tested under the common loading path for all constant $\sigma_{3}$ levels: experimental data in solid dots and predictions using the modified-MNLD failure criterion in dashed curves. 

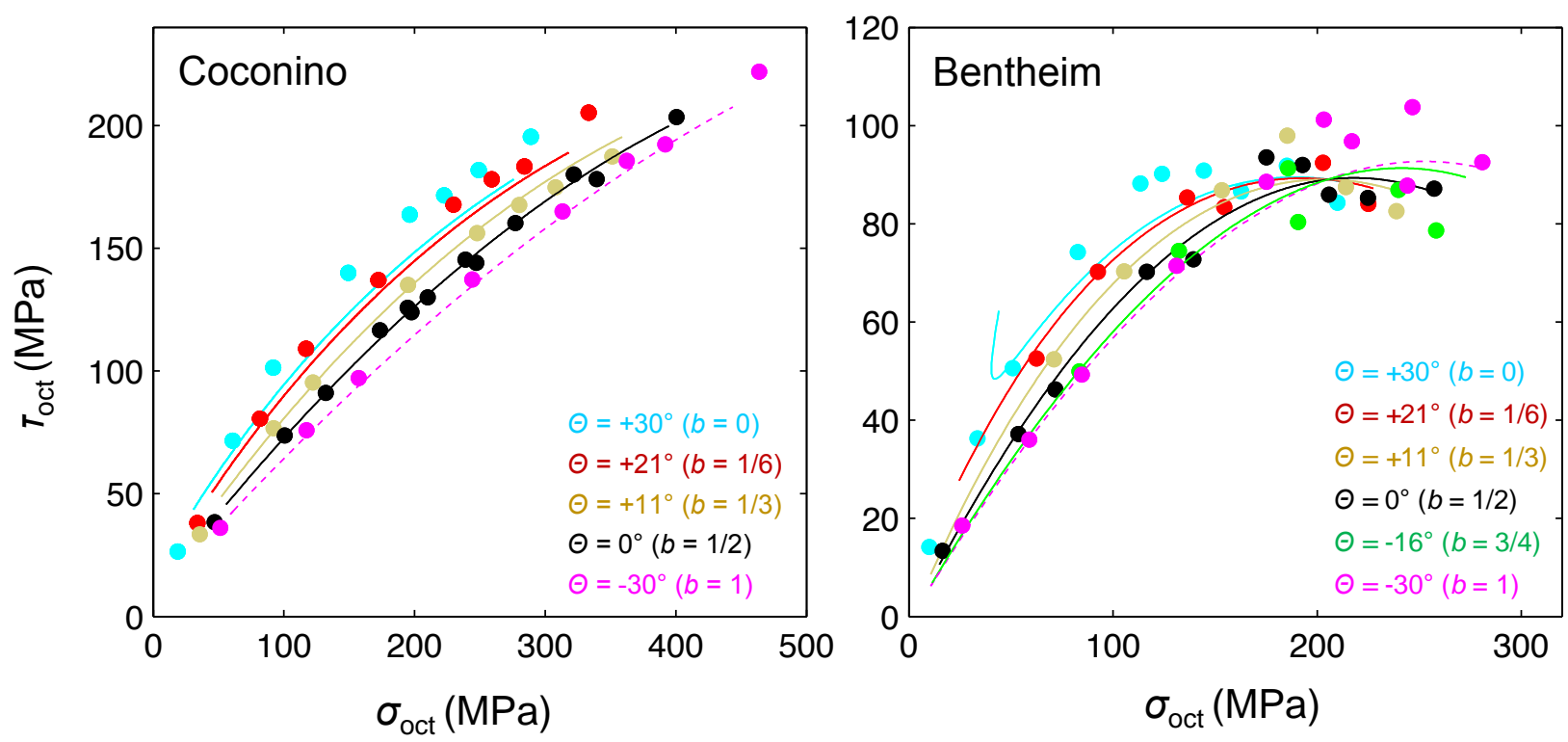

Figure 3. Variations of the octahedral shear stress at failure $\left(\tau_{\text {oct }}\right)$ with the octahedral normal stress at failure $\left(\sigma_{\text {oct }}\right)$ in Coconino and Bentheim sandstones: experimental data in solid dots and the predictions using the modified-MNLD failure criterion in solid curves for each constant Lode angle. 
(a)

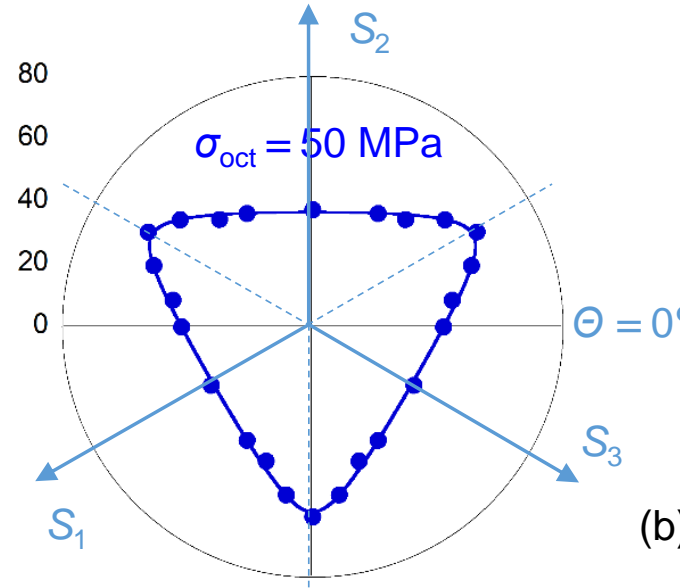

(b)

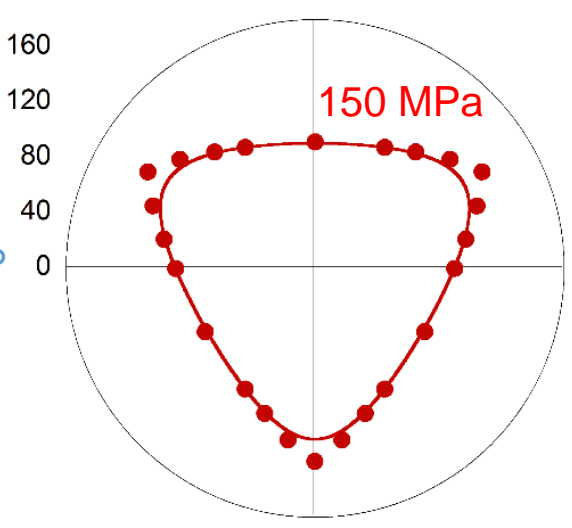

(c)

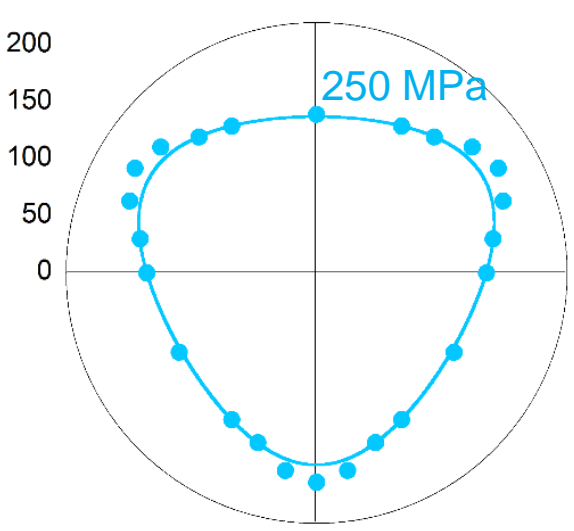

(d)

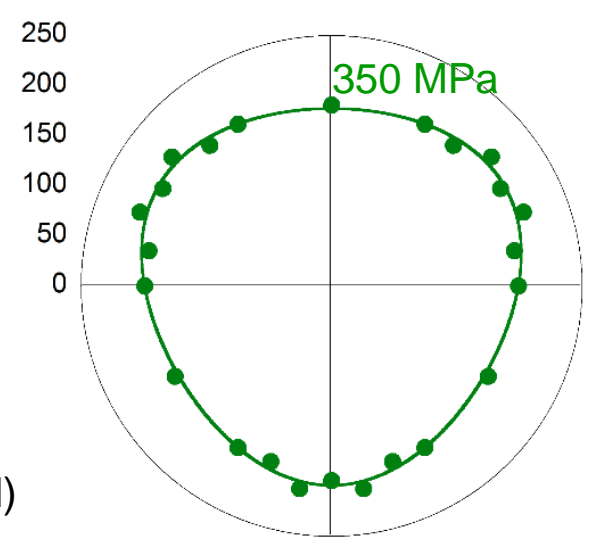

(e)

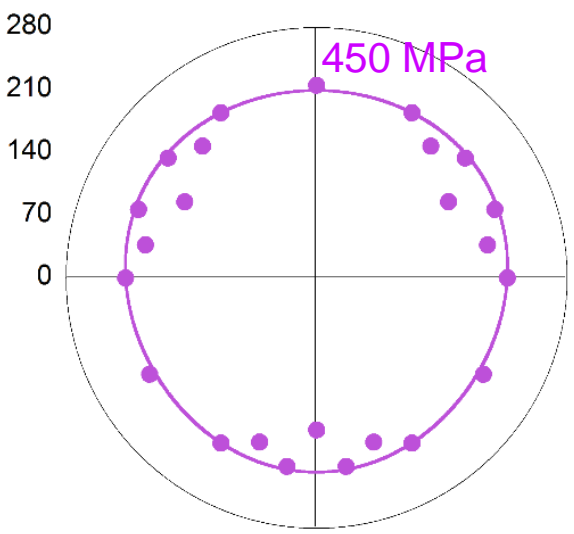

Figure 4. Comparison of stress conditions at failure in the deviatoric planes $\left(\tau_{\text {oct }}\right.$ - $\Theta$ domain) between the empirically-fitted novel loading path test data (solid dots) and the predicted failure surface (solid curve) in Coconino sandstone for constant $\sigma_{\text {oct }}=50,150,250,350$, and $450 \mathrm{MPa}$. 
(a)

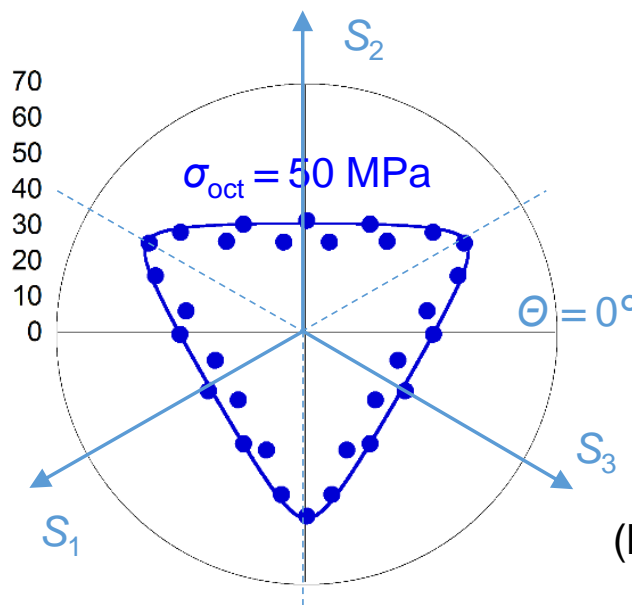

(b)

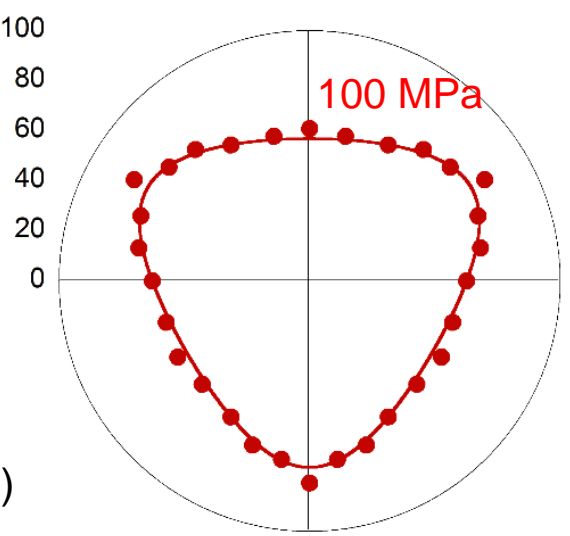

(c)

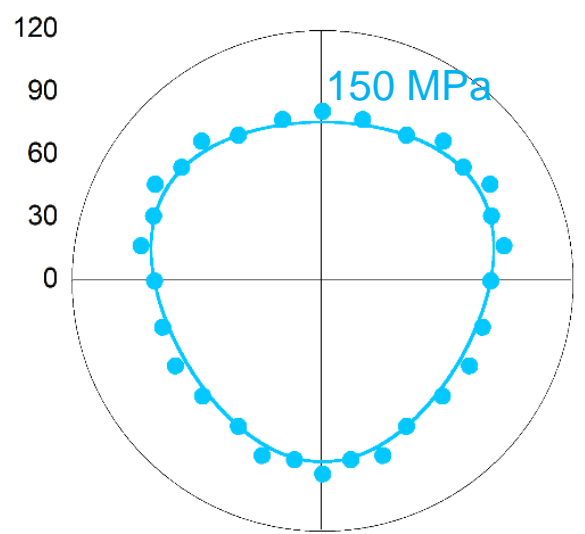

(d)
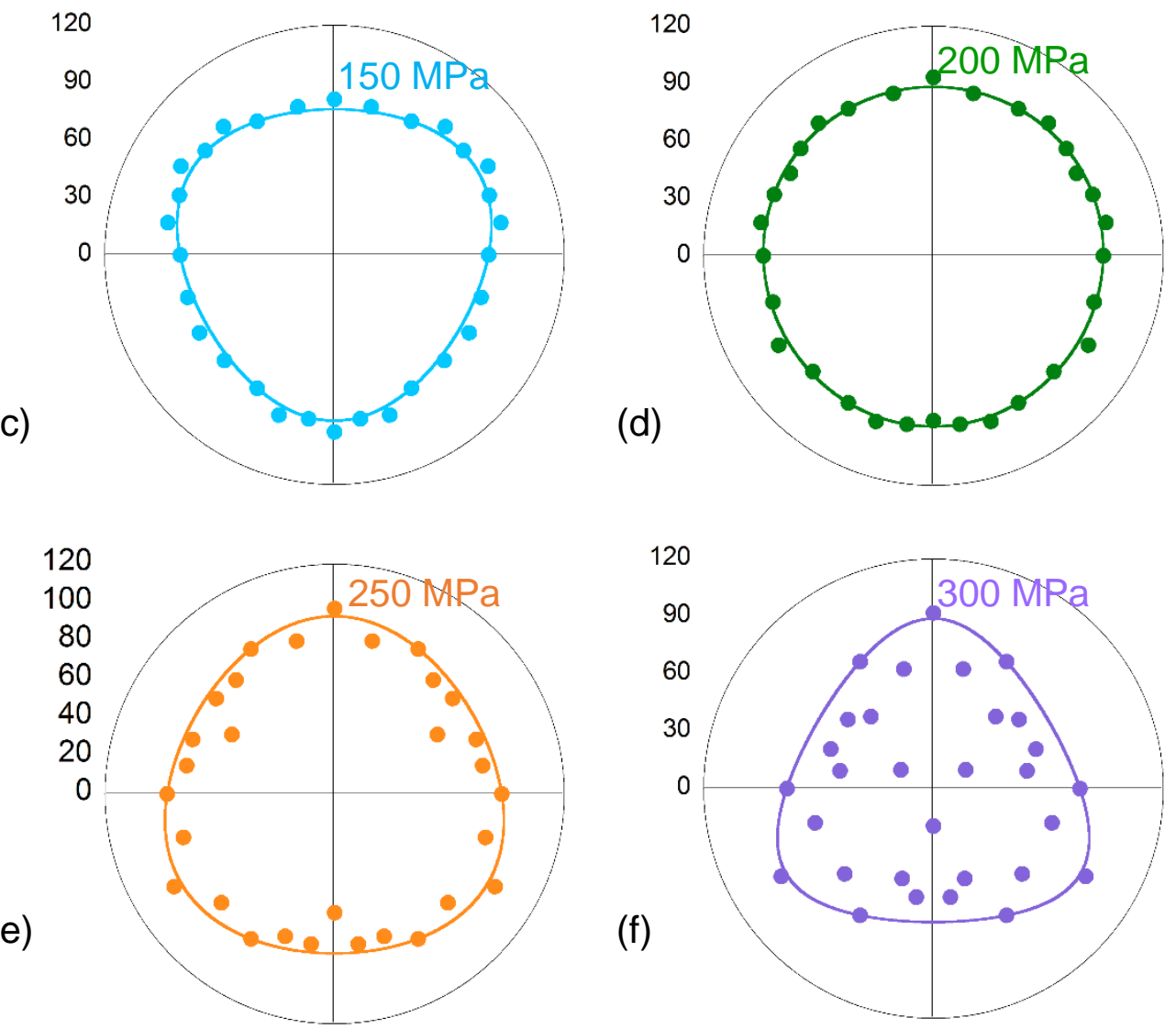

(f)

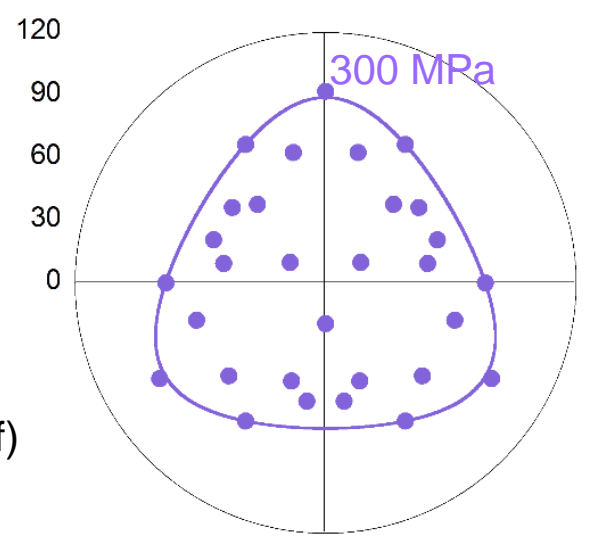

Figure 5. Comparison of stress conditions at failure in the deviatoric planes $\left(\tau_{\text {oct }}{ }^{-}\right.$ $\Theta$ domain) between the empirically-fitted novel loading path test data (solid dots) and the predicted failure surface (solid curve) in Bentheim sandstone for constant $\sigma_{\text {oct }}=50,100,150,200,250$, and $300 \mathrm{MPa}$. 

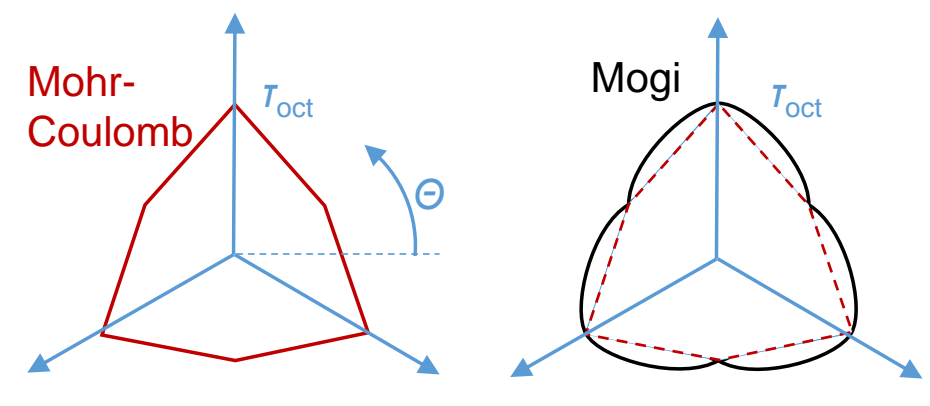

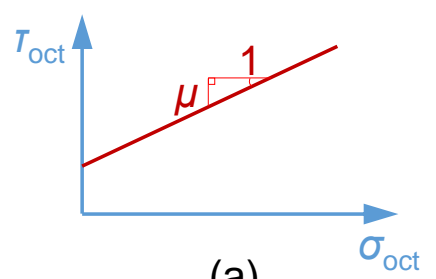

(a)

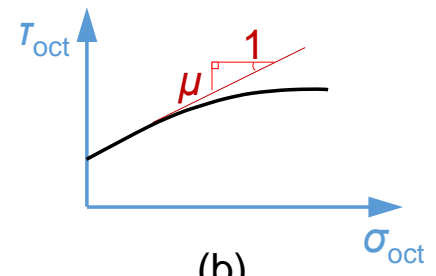

(b)

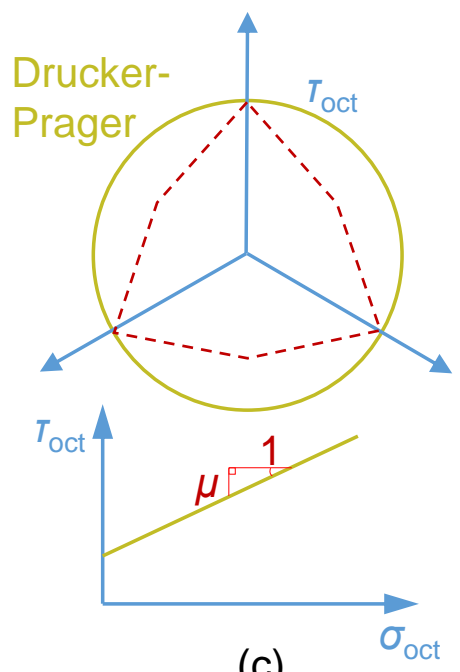

(c)
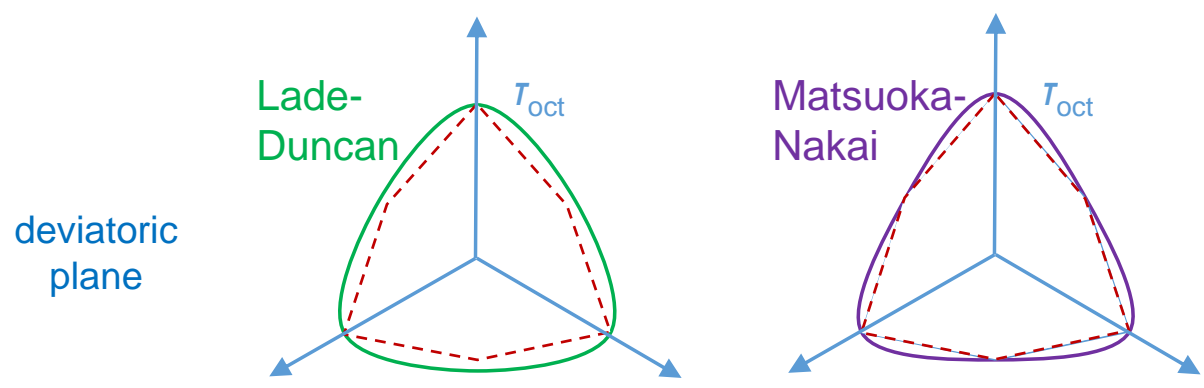

meridian plane

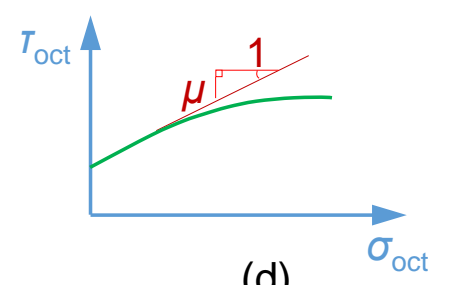

(d)

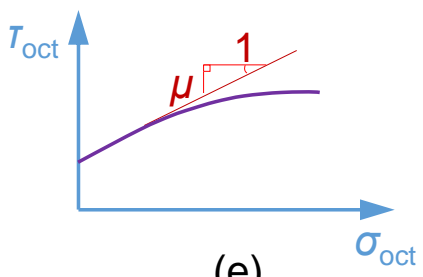

(e)

Figure 6. Typical failure envelope shapes in the deviatoric plane ( $\tau_{\text {oct }}-\Theta$ domain) and the meridian plane ( $\tau_{\text {oct }}-\sigma_{\text {oct }}$ domain) of some common failure descriptions: (a) Mohr-Coulomb; (b) Mogi; (c) Drucker-Prager; (d) Lade-Duncan; (e) MatsuokaNakai. The irregular hexagon failure envelop of Mohr-Coulomb (in red) in the deviatoric plane was repeated (in dash) in (b) through (e) for comparison. 


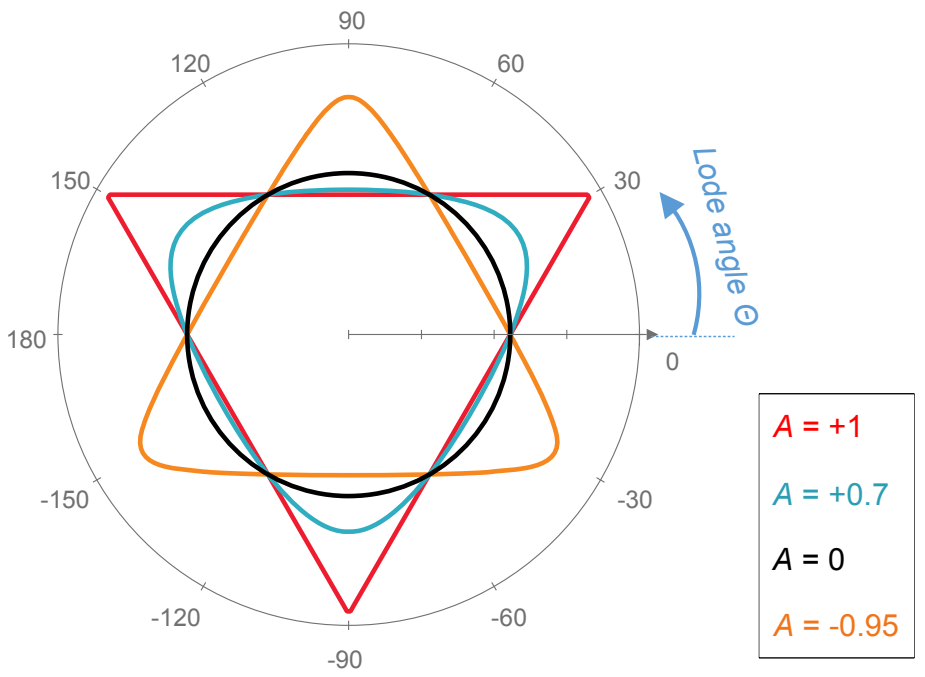

Figure 7. Variations of the failure envelope shape with parameter $A$ on the deviatoric plane. The envelopes were set to converge at pure shear in order to facilitate comparison. Note as $A$ moves away from 0 , the envelope becomes increasingly distorted into triangular shape. 


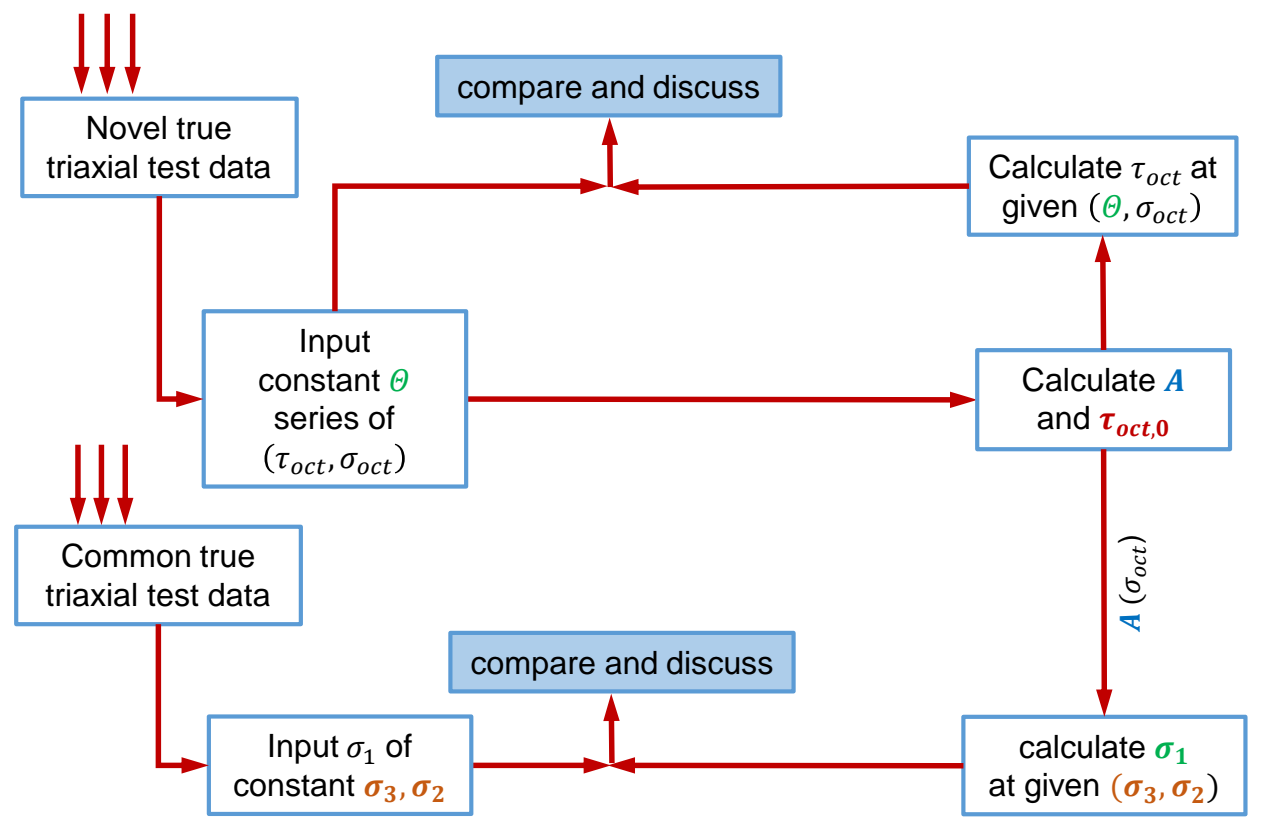

Figure 8. Flowchart illustrating the procedure of failure prediction using the modified-MNLD failure criterion against common and novel loading path test data. 

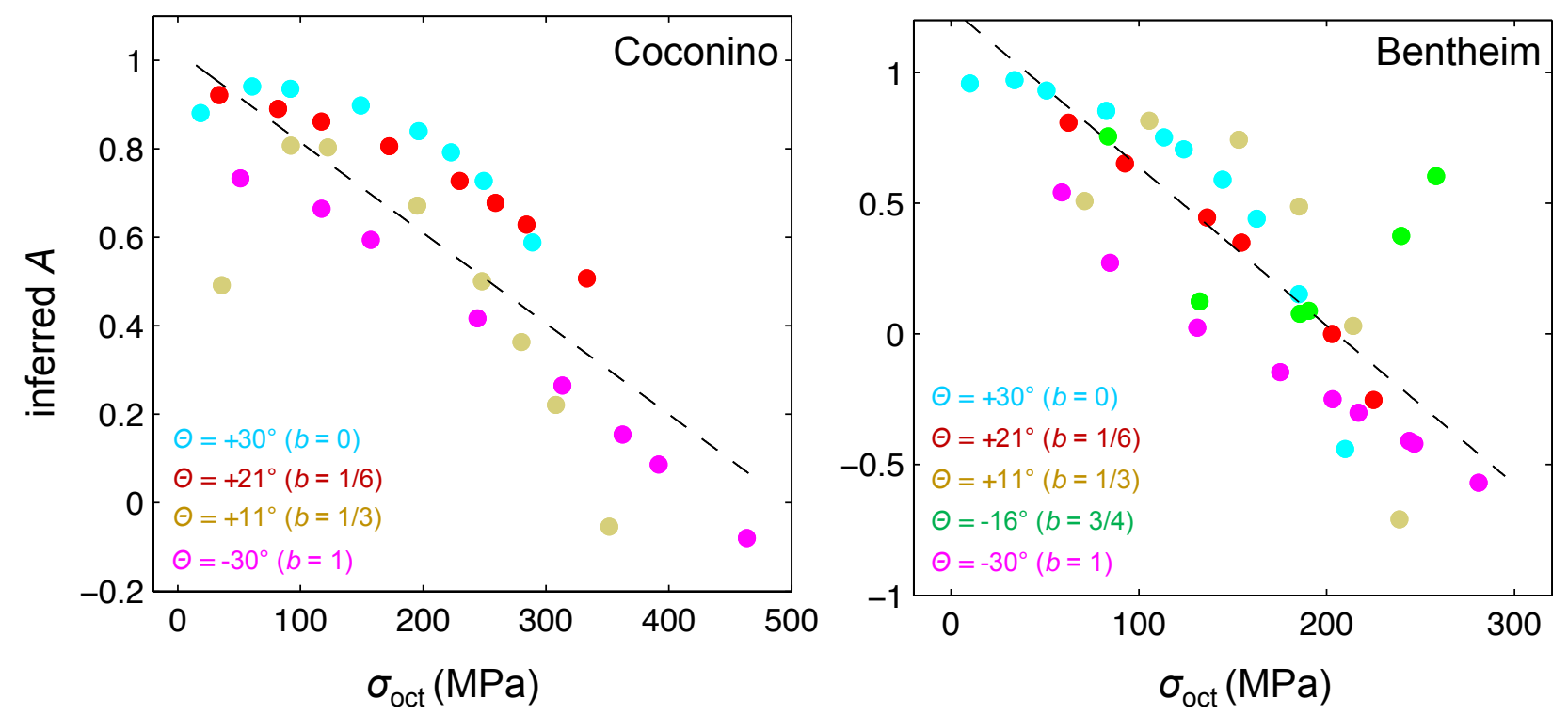

Figure 9. Variations of inferred $A$ value with the octahedral normal stress at failure $\left(\sigma_{\text {oct }}\right)$ for all constant Lode angles (excluding $\Theta=0^{\circ}$ ) in Coconino and Bentheim sandstones: the dashed line represents the best linear regression of all data points. 
Coconino sandstone
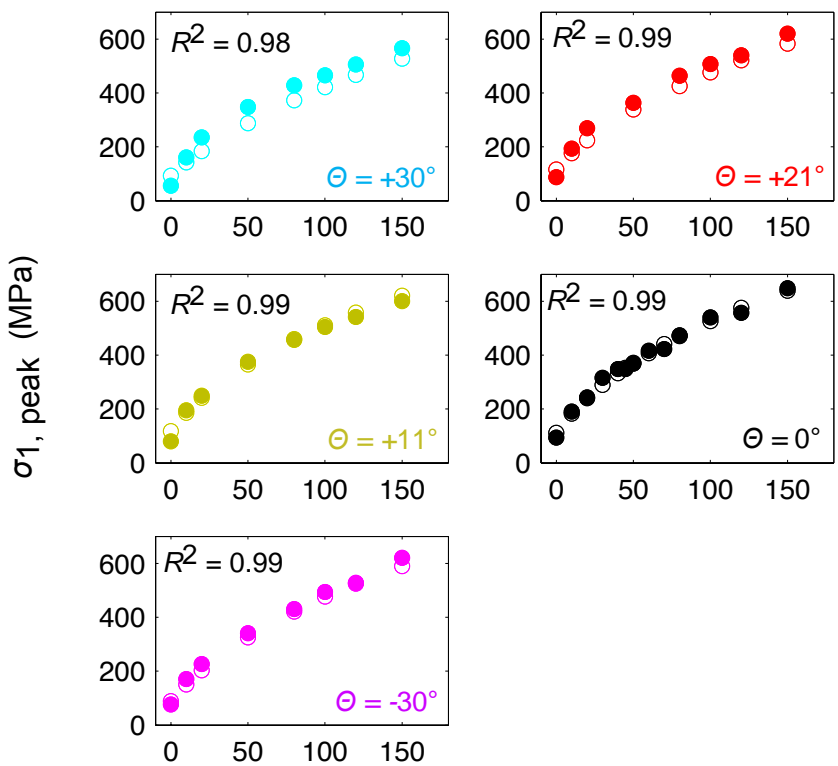

$\sigma_{3}(\mathrm{MPa})$
Bentheim sandstone
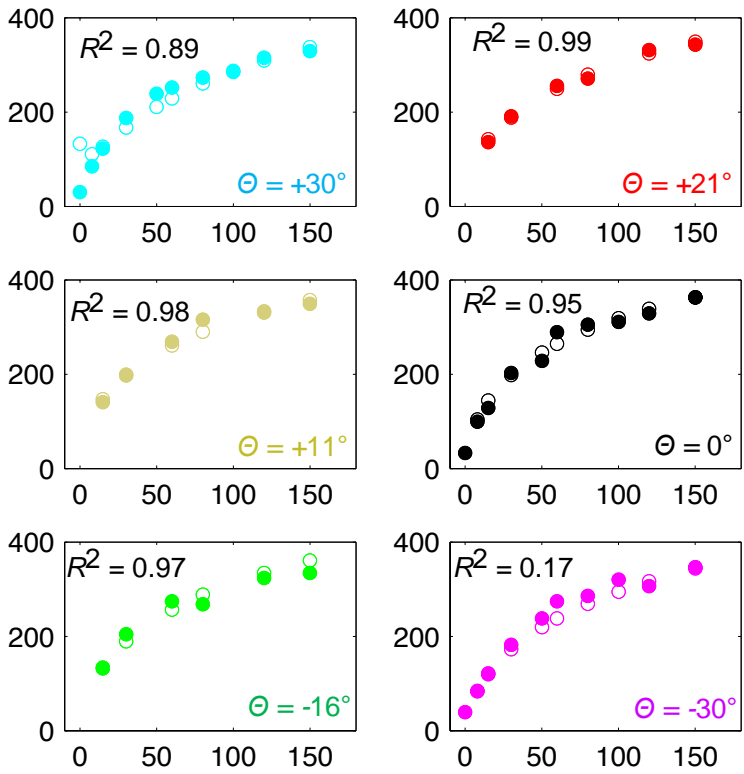

$\sigma_{3}(\mathrm{MPa})$

Figure 10. Variations of $\sigma_{1 \text {,peak }}$ with $\sigma_{3}$ for each constant Lode angle $\Theta$ under the novel loading path in Coconino sandstone (left) and Bentheim sandstone (right). The predicted conditions are open circles and the experimental results are solid dots. 


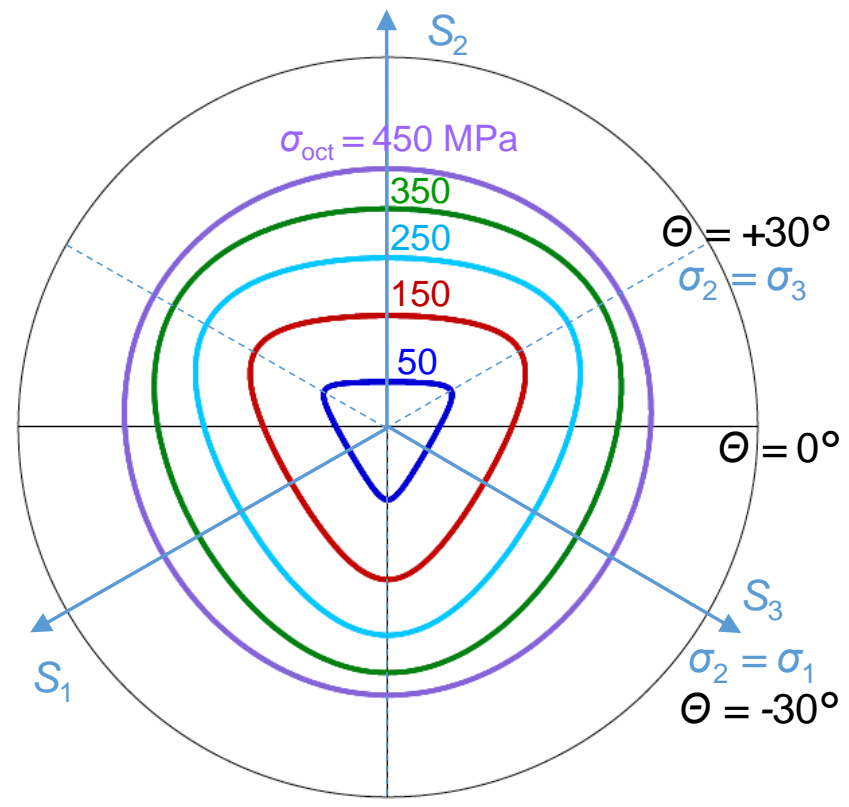

Coconino

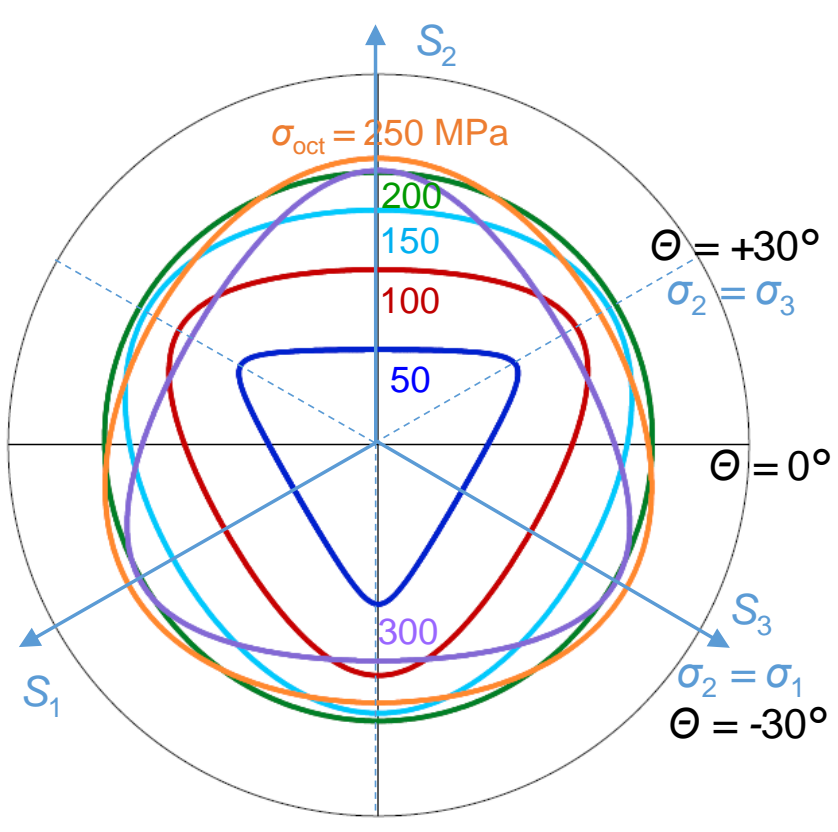

Bentheim

Figure 11. Predicted evolution of failure surface shapes of the Coconino and Bentheim sandstones on successive deviatoric planes ( $\tau$ oct - $\Theta$ domain) projected on the $\pi$-plane. 